\title{
TRYPSIN AND ANTITRYPSIN
}

By S. G. HEDIN

From the Lister Institute of Preventive Medicine

(Received August roth, 1906)

In a previous paper ${ }^{\mathrm{I}} \mathrm{I}$ have given an account of experiments on the antitryptic action of serum-albumin, the main results of which were :-

(I) If the trypsin and the antibody are mixed before they are added to the substrate, then the neutralising effect of the antibody is larger than if they are added separately. (2) The effect increases up to a certain point, when the trypsin and the antibody are kept in contact before the addition of the substrate. (3) The maximum effect of the antibody is larger the higher the temperature. The effect corresponding to a certain temperature increases if the temperature is raised, but remains the same if the temperature is lowered.

The continuation of these experiments is given in the following paper. The estimation of the digesting power was carried out by precipitating the samples to be compared with equal volumes of tannic acid solution and determining the nitrogen in equal volumes of the filtrates ${ }^{2}$. Therefore the figures given represent the number of cubic centimetres of decinormal acid, corresponding to the nitrogen in equal volumes of the tannic acid filtrate. In all experiments the antibody was allowed to act upon the trypsin before the substrate (casein) was added. It may be pointed out that the proteid in the antibody solution (the serumalbumin dialysed free from salt) is practically indigestible, unless a very large excess of trypsin is used. An amount of trypsin, which with an excess of casein would have given the effect 90 , gave with Io c.c. of antibody the effect $0^{\circ} \mathbf{2}$.

I. Fourn. of Physiol., Vol. XXXII, p. 390, 1905.

2. The tannic acid solution contained in two litres : $200 \mathrm{grs}$ tannic acid, 100 c.c. glacial acetic acid, 50 grs. sodium chloride, and 50 grs. sodium acetate. 
The Influence of the Concentration of the TrypsinAntitrypsin Mixture on the Amount of Trypsin Neutralised.

That concentration effects no material influence is borne out by the following experiments :-

Experiment I.-In this experiment the ratio between the concentrations to be compared was $2: 1$. Two sets of specimens containing the one (A) 50 c.c. tryps. + Io c.c. (antib. $+\mathrm{H}_{2} \mathrm{O}$ ), and the other (B) 50 c.c. tryps. + Io c.c. (antib. $+\mathrm{H}_{2} \mathrm{O}$ ) +60 c.c. $\mathrm{H}_{2} \mathrm{O}$, were prepared and kept at $2 \mathbf{r}^{\circ}$. After the intervals of time recorded Io c.c. of the specimens of set A, together with 10 c.c. of water, were added to 50 c.c. of casein solution. Of the specimens of set $\mathrm{B}, 20$ c.c. were added to the same amount of casein. After 24 hours at $37^{\circ}$, the nitrogen was determined in equal volumes of the tannic acid filtrates.

\begin{tabular}{|c|c|c|c|c|c|}
\hline \multirow{2}{*}{\multicolumn{2}{|c|}{0.625 c.c. antib. }} & A & $\begin{array}{c}20 \mathrm{~min} . \\
36.05\end{array}$ & $\begin{array}{c}4 \text { hours. } \\
36 \cdot 25\end{array}$ & 24 hours. \\
\hline & & B & $36 \cdot 35$ & 35.9 & - \\
\hline \multirow[t]{2}{*}{$1 \cdot 25$} & \multirow[t]{2}{*}{$"$} & A & $32 \cdot 65$ & $33 \cdot 2$ & - \\
\hline & & B & $32 \cdot 45$ & $32 \cdot 65$ & - \\
\hline \multirow[t]{2}{*}{$2 \cdot 5$ c.c. } & $"$ & A & $20 \cdot 0$ & $20 \cdot I$ & - \\
\hline & " & B & 19.55 & $19 \cdot 2$ & - \\
\hline \multirow{2}{*}{5 c.c. } & \multirow[t]{2}{*}{ " } & A & 8.2 & $6 \cdot 25$ & 6.0 \\
\hline & & B & $8 \cdot 4$ & 6.75 & 5.5 \\
\hline \multirow[t]{2}{*}{ Io c.c. } & \multirow[t]{2}{*}{ " } & A & $5 \cdot 35$ & 4.55 & 4.4 \\
\hline & & B & 5.4 & $4^{\cdot 8}$ & $4 \cdot 15$ \\
\hline
\end{tabular}

In the specimens with $0.625,1 \cdot 25$ and 2.5 c.c. of antibody, the final state of equilibrium was reached in $20 \mathrm{~min}$., but not in those with larger amounts of antibody. In no case can any influence of the concentration be observed.

Experiment II.-Ratio between concentrations $4:$ I. Mixtures kept at $37^{\circ}$.

(A) 20 tr. +100 antib.

(B) 20 tr. +100 antib. $+360 \mathrm{H}_{2} \mathrm{O}$.

Of $A, 25$ c.c., and of B, I00 c.c. were taken for digestion as above.

$\begin{array}{clcc} & 5 \text { min. } & 30 \text { min. } & \text { I Hour } \\ \text { A } & 4 \cdot 6 & 3 \cdot 8 & 3 \cdot 75 \\ \text { B } & 4 \cdot 85 & 4 \cdot 4 & 4^{\cdot 2}\end{array}$


Of the same agents another two mixtures were prepared:

(A) 20 tr. + I antib.

(B) 20 tr. + I antib. $+63 \mathrm{H}_{2} \mathrm{O}$.

and 5 resp. 20 c.c. taken for digestion.

$\begin{array}{lll} & 5 \mathrm{~min} . & 30 \mathrm{~min} . \\ \text { A } & 32 \cdot 95 & 32 \cdot 45 \\ \text { B } & 32 \cdot 4 & 32 \cdot 05\end{array}$

It must be borne in mind that Experiments $I$ and 2 were carried out with such small amounts of casein that the results are not proportional to the amounts of active trypsin present, ${ }^{1}$ and therefore, the results do not allow of any conclusions as to the relative amounts of trypsin neutralised by different amounts of antibody.

Can any of the Agents (Trypsin or Antibody) be completely Neutralised ?

My investigations on this subject show, that when little antibody is used, then the antibody can be completely neutralised, as proved by the fact that fresh trypsin added develops its full activity. In the cases tried more than three-quarters of the whole amount of trypsin could be neutralised without leaving any free antibody. On the other hand, if much antibody is used, then some antibody remains free, the fluid showing strongly antitryptic action upon added trypsin; at the same time the fluid manifests some tryptic activity even after 24 hours in presence of very large amounts of antibody. In short, the antibody can be completely neutralised by using a sufficient amount of trypsin, whilst it is impossible to neutralise all trypsin by an excess of antibody.

Two series of experiments bearing on this subject are recorded below. In these, such an excess of casein was used that the tryptic effect was proportional to the active trypsin present. ${ }^{2}$ This was proved to be the case by the following experiment, where the effects of 2.5 and 5 c.c. of trypsin were found to be $25 \cdot 7$ resp. $5 \mathrm{I}^{\circ} 7$. Therefore all figures less than $5^{\circ} 7$ are inside the range of proportionality.

I. Hedin, 'Observations on the action of trypsin,' Journ. of Physiol., Vol. XXXII, p. 468, 1905.

2. Journ. of Physiol., Vol. XXXII, pp. 471-474, 1905. 
Experiment III.-Each specimen contained 300 c.c. casein + Io c.c. (tryps. $+\mathrm{H}_{2} \mathrm{O}$ ) + I c.c. (antib. $+\mathrm{H}_{2} \mathrm{O}$ ). The trypsin or, in case the trypsin was added in two lots, the first lot of it, the antibody and the water were kept for two hours at $37^{\circ}$, then the second lot of trypsin was added, and all specimens were kept for another hour at $37^{\circ}$ before the casein was added. The digestion lasted for 24 hours. I 50 c.c. tannin acid solution and 300 c.c. filtrate were taken for each analysis.

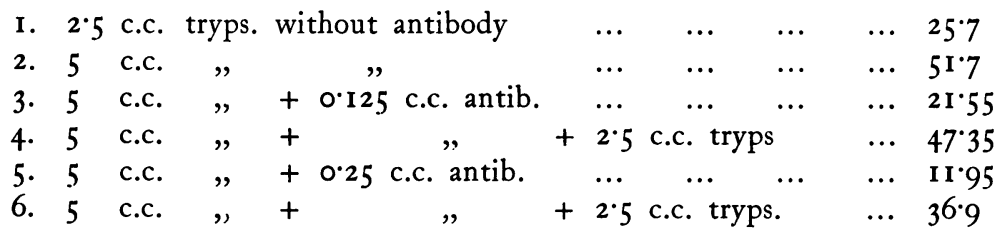

The effect of an addition of $2 \cdot 5$ c.c. of trypsin is $47 \cdot 35-2 \mathrm{I}^{\cdot} 55$ $=25^{\circ} 8$ in Specimen 4 , and 36.9 - I I.95 $=24^{\circ} 95$ in Specimen 6, as against 25.7 in Specimen I without antibody, showing that in both cases the antibody was completely engaged before the second lot of trypsin was added.

Experiment IV was carried out like Experiment III, only with another enzyme.

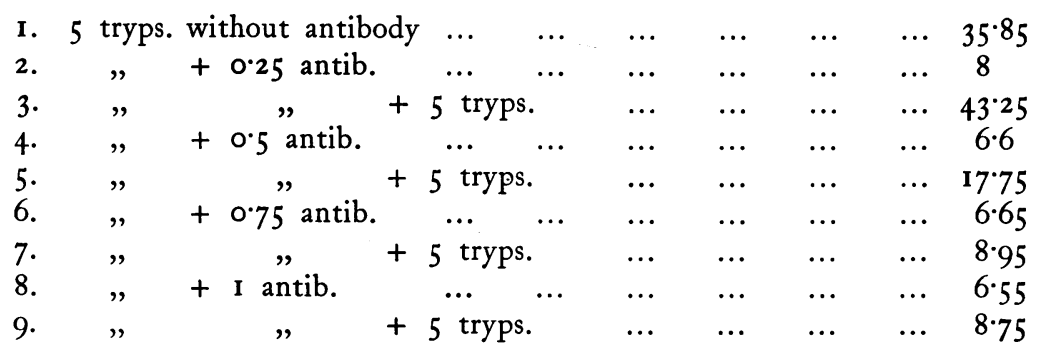

Specimen 3 shows that the addition of 5 c.c. of trypsin to Specimen 2, gives the effect $43 \cdot 25-8=35^{\cdot 25}$, or practically the same effect as 5 tryps. without the presence of antibody $(35.85$ in Specimen I). On the other hand, Specimens 4-9, which all contained more antibody than 0.25 c.c., show that the effect of the second lot of trypsin was not nearly the same as without antibody. Therefore, in Specimens 5, 7; 9, there was active antibody present, when the second lot of trypsin was added. 
Experiment $V$ was carried out with large amounts of antibody and long time of interaction of the agents. The specimens contained : 100 c.c. cas. +12 c.c. (tryps. $+\mathrm{H}_{2} \mathrm{O}$ ) +3 c.c. (antib. $+\mathrm{H}_{2} \mathrm{O}$ ).

Trypsin and antibody were kept at $37^{\circ}$ for 24 hours, then the second lot of trypsin and the casein were added. After 24 hours' digestion, 50 c.c. tannic acid solution were added and roo c.c. filtrate were taken for analysis.

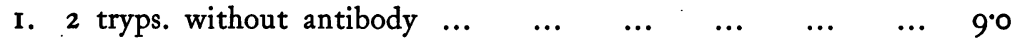

Therefore to c.c tryps. corresponds to $\quad \ldots \quad \ldots \quad \ldots \quad 45^{\circ}$

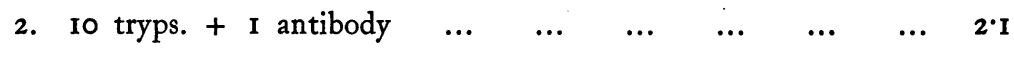

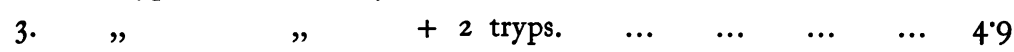

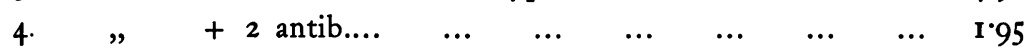

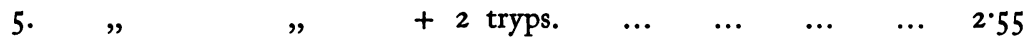

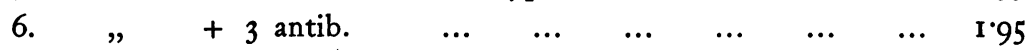

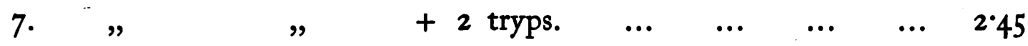

The figures obtained indicate that in Specimens 2, 4, 6 there was free trypsin and free antibody present at the same time.

\section{The Amount of Trypsin Neutralised by a certain Amount of Antibody}

Experiments bearing on this point show, that when different amounts of antibody are made to act upon the same amount of trypsin, then the effect of a small amount is always greater per unit of antibody. In the experiments such an amount of casein was used that the results obtained were proportional to the active amount of trypsin present.

Experiment VI.-This experiment is the same as Experiment III, only with the results differently arranged and with an additional set of specimens containing Io c.c. of trypsin.
I. 5 tryps. +0 antib. ... $51 \cdot 7$
4. Io tryps. +0 antib. ... $103 \cdot 4^{1}$
2. $"+0.125 \# \quad \ldots \quad 21.55$
5. $\quad+0.25 \quad \ldots \quad 44^{\cdot I}$
3. $\quad+0.25 \quad, \quad \ldots \quad$ II 95
6. $\quad+0.5 \quad, \quad \ldots \quad 25.95$

According to Experiment III, the Specimens 2 and 3 contained no free antibody. The same, therefore, must have been the case with 5 and 6, which had the double amounts of agents and gave approximately the double effect. Therefore, on complete binding, the

I. Since this figure lies outside the range of proportionality, it has been calculated by doubling the effect of 5 c.c. of trypsin. 
neutralising effect of 0.125 c.c. of antibody is found to be 30.15 from I and 2 , and 9.6 from 2 and 3 , and for 0.25 c.c. of antibody one obtains the effect $59^{\circ} 3$ from 4 and 5 , and $18 \cdot 15$ from 5 and 6 .

Experiment VII is the same as Experiment IV, with an additional set of specimens.

$\begin{array}{ccccc}5 \text { tryps. } & +\circ & \text { antib. } & \ldots & 35.85 \\ " & +0.25 & \# & \ldots & 8 \\ " & +0.5 & \# & \ldots & 6.6 \\ " & +0.75 & \# & \ldots & 6.65 \\ " & +\mathrm{I} & \# & \ldots & 6.55\end{array}$

$$
\begin{aligned}
& \text { Io tryps }+0 \text { antib. } \ldots 7 \quad \mathbf{I}^{1} 7^{1} \\
& \text {, } \quad+0.25 \quad, \quad \cdots \quad 4 \mathbf{r}^{\circ} 95 \\
& \begin{array}{lllll}
n & +0.5 \quad \ldots & \ldots & 15.65
\end{array} \\
& \text { ” } \quad+0.75 \quad, \quad \ldots \quad 9.6 \\
& \text {, } \quad+1 \quad, \quad \ldots \quad 9.5
\end{aligned}
$$

The figures obtained illustrate the above rule without any further explanation. In both sets, with large amounts of antibody, a state of neutralisation was arrived at which was not altered on addition of more antibody.

\section{Destruction of the Antibody}

The antitryptic properties of the serumalbumin are destroyed on boiling, and even on heating to a lower temperature, as shown by Cathcart. ${ }^{2}$ At bloodheat it is readily destroyed by $0.2 \%$ acetic acid, as shown by following experiments.

The antibody was kept with $0.2 \%$ acetic acid at $37^{\circ}$. After intervals of time recorded, samples were taken, from which the acid was removed by dialysis, whereupon the neutralising effect upon trypsin was tried. After the antibody had been acting upon the trypsin for 2 hours at $37^{\circ}$ the amount of trypsin left free was determined with 200 c.c. of casein solution. The results were :-

$$
\begin{aligned}
& \begin{array}{lllllll}
\text { Without antibody } & \ldots & \ldots & \ldots & \ldots & \ldots & 55.5
\end{array} \\
& \begin{array}{llllll}
\text { With } 5 \text { c.c. intact antibody } \ldots & \ldots & \ldots & \ldots & 2 \cdot I
\end{array} \\
& \text {, }, \quad \text { treated with acetic acid for } 3 \text { hours } \quad 45^{\circ} 9 \\
& \text { " " " }, 6 \quad \text { " } 64.7
\end{aligned}
$$

In another experiment, the same antibody was treated with acetic acid for 8 hours :-

$\begin{array}{lllllllll}\text { Without antibody } & \ldots & \ldots & \ldots & \ldots & \ldots & \ldots & 3595\end{array}$

With antibody treated with acetic acid for 8 hours $\quad \ldots \quad 35.45$

\footnotetext{
I. Since this figure lies outside the range of proportionality, it has been calculated by doubling the effect of 5 c.c. of trypsin.

2. Journ. of Physiol., Vol. XXXI, p. 495, 1904.
} 
Therefore the antibody is practically destroyed by $0.2 \%$ acetic acid during 8 hours at $37^{\circ}$.

Having thus found that acetic acid readily destroys the antibody and knowing that trypsin is only very slowly attacked by this acid, I thought it important to try whether, in a mixture of trypsin and antibody, which has been kept till the antibody has reached its maximum of effect, the trypsin can be rendered active again by treatment with $0.2 \%$ acetic acid at $37^{\circ}$. With this view, I have carried out several experiments, and I have been able to recover the trypsin in none of them. The figures obtained in one of them were as follows :

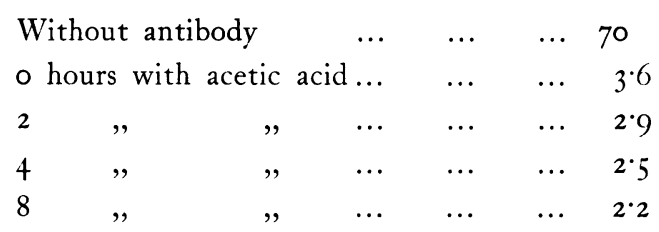

The slight fall in the activity of the mixture might depend upon the destructive influence of the acetic acid upon the trypsin not neutralised by the antibody ${ }^{\mathrm{T}}$.

Since some time is always required before all of the antibody is destroyed by the acetic acid, the antibody exercises some neutralising effect even in presence of acetic acid.

\section{Discussion of the Results}

It is generally assumed that enzymes, previous to their action, are in some way attached to the substrate they are able to act upon. On the other hand, antibodies are supposed to form a kind of combination with the substances they neutralise, thus preventing them from being attached to the substrate. My observations, that the amount of trypsin neutralised is larger when the antibody is allowed to act upon the trypsin in absence of a proteid than in presence of the same (p. 474), are quite consistent with these views.

1. With regard to this experiment it may be noted that Morgenroth on treating the compound cobrahaemolysin-antibody and cobraneurotoxin-antibody with $\mathrm{HCl}$ was able to recover all of the haemolysin and 50 per cent. of the neurotoxin, Berl. Klin. Wochenschr, 1905, No. 50, and 'Weitere Beiträge zur Kenntniss der Schlangengifte und ihrer Antitoxine'; Arbeiten aus dem Pathol. Inst. zu Berlin, .1906. 
From the fact that the neutralising effect of the antibody is independent of the dilution (p. 475), one must conclude that the compound which might be formed is not subject to decomposition with water (hydrolysis). There are two other reasons which make me believe that the compound, once formed, does not give off any active trypsin to water. These are :-

I.-The antibody neutralises more trypsin the higher the temperature. Nevertheless, if a mixture of trypsin and antibody is kept at a certain temperature till a constant state of neutralisation has been reached, then no trypsin is liberated on lowering the temperature (p. 474).

2.-The antibody is readily destroyed by the action of weak acetic acid at $37^{\circ}$. If a mixture of trypsin and antibody, having been kept at $37^{\circ}$ till no more trypsin is neutralised, is digested with weak acetic acid, then no trypsin is rendered active (p. 480).

It must, however, be borne in mind, that the way in which my experiments have been carried out does not exclude the possibility that, after the addition of casein, some trypsin might be transferred from the antibody to the casein. If the antibody readily gave off the trypsin, then the distribution of the trypsin would become the same as if the casein had been present from the very beginning. The fact that this is not the case shows that the trypsin, when once attached to the antibody, is not readily given off to casein. Nevertheless, it cannot be entirely excluded that some change may take place, and a transport of trypsin from the antibody to the casein might, perhaps, account for the fact that it has been found impossible completely to neutralise trypsin by means of the antibody (p. 476).

Since trypsin and its antibody undoubtedly, in more than one respect, behave in a way similar to some toxins and their antitoxins, it might be useful to consider the question, whether the theories put forth for the explanation of the relationship between the latter might apply to the trypsin and its antibody.

According to Ehrlich's theory, ${ }^{1}$ the compound toxin-antitoxin is

I. Fortschritte d. Med., 1897; Werthbestimmung des Diphteriheilserums, 1897 . 
merely a chemical one, like the combination between a strong base and a strong acid. This theory, therefore, involves that the two constituents should combine till one of them is completely bound up and that they by proper means can be separated again. Moreover, Ehrlich assumes that some toxins (e.g. diphteriatoxin) are made up of constituents of different toxicity and different avidity to the antibody. By aid of this theory it might be explained that a large amount of trypsin can be neutralised without leaving any antibody free, but the fact that on further addition of antibody the fluid may contain free trypsin and free antibody at the same time this theory does not account for, unless one assumes that trypsin is made up of different constituents. Furthermore, the fact that I have not been able to separate the two constituents of the trypsin-antitrypsin compound is not in favour of Ehrlich's theory.

Arrhenius and Madsen ${ }^{1}$ assume that toxin and antitoxin behave like a weak base and a weak acid. Therefore, the compound is subject to hydrolysis, and there always exists some free toxin and some free antitoxin at the same time. Moreover, their theory requires that the compound should be reversible, i.e., the equilibrium ought to be the same under the same conditions, no matter in which way they have been arrived at. This theory seems to be inconsistent with the fact that I have been able to neutralise more than three-quarters of the trypsin without any antibody remaining free in the fluid. In addition, the compound has not been found to be reversible in my experiments (p. 48I).

Bordet has suggested that the antibodies be capable of combining with varying amounts of toxin, and consequently he holds that the combination toxin-antitoxin be not a chemical one. He assumes that the toxin is taken up by the antitoxin, very much as a dye is by a tissue. This view takes into account the fact that the agents, being colloids, may, perhaps, not follow the laws of genuine solutions. ${ }^{2}$ This view has more recently been advanced by Nernst ${ }^{3}$ and by Craw. ${ }^{4}$

1. Festskrift ved invielsen af statens seruminstitut, Copenhagen, p. 56, 1902.

2. Ann. Inst. Past., Vol. XVII, p. 16I, 1903.

3. Zeitschr. physik. Chem., Vol. XLVII, p. 54, 1904.

4. Proc. Roy. Soc., Vol. LXXVI, B, p. $179,1905$. 
Trypsin and antitrypsin, being colloids, do not form any real solutions with water, but only suspensions of larger or smaller particles. Since very little is known as to the ways in which suspended particles might act upon each other, I have tried to throw some light upon this subject by investigating how charcoal acts upon trypsin, thus substituting charcoal for the tryptic antibody in my above experiments. The results are laid down in the following paper and the further discussion of the subject must be postponed till the account of these experiments has been given.

The results of my previous investigations on trypsin and antitrypsin are given on p. 474. The conclusions of the investigations in this paper are as follows :-

I.-The amount of trypsin neutralised by the antibody is independent of the dilution.

2.-The antibody can be completely saturated by using a sufficient amount of trypsin; on the other hand it has been found impossible under the conditions used, completely to neutralise trypsin by an excess of antibody.

3.-The amount of trypsin neutralised by a certain amount of antibody is not constant, a small amount of antibody neutralising relatively more trypsin than a larger.

4.-The antibody can be completely destroyed by $0^{\circ} \mathrm{I}-0.2 \%$ of acetic acid at $37^{\circ}$ for about 8 hours.

5.-When trypsin has been neutralised by the antibody, it has been found impossible by the means tried to render it active again. 